\title{
Introduction to Constructal Law Analysis for a Simplified Hourly Energy Balance Model of Residential Buildings at District Scale
}

\author{
Guglielmina Mutani*, Valeria Todeschi, Giulia Grisolia, Umberto Lucia \\ Dipartimento Energia "Galileo Ferraris", Politecnico di Torino, Corso Duca degli Abruzzi 24, 10129 Torino, Italy \\ Corresponding Author Email: guglielmina.mutani@polito.it
}

https://doi.org/10.18280/ti-ijes.630102

Received: 22 January 2019

Accepted: 20 March 2019

\section{Keywords:}

buildings morphology, constructal law, residential buildings, space heating consumption model, urban scale

\begin{abstract}
The energy consumption of buildings is related to multiple factors, such as construction and geometric characteristics, occupancy, climate and microclimate conditions, solar exposure, and urban morphology. Therefore, the interaction between buildings and their surroundings should be taken into consideration.

The aim of this work is to create a bottom-up model at urban scale to evaluate the energy balance of residential buildings starting from their hourly consumption data. The model of hourly energy consumption presents some simplifications to be applied on an urban scale and introduces some variables at block of buildings scale (e.g. sky view factor and canyon height to width ratio). A Geographical Information System was used to localize the data and to provide information on how the shape of the city affects buildings consumption.

The new model was verified on about 50 residential buildings for two consecutive heating seasons in the city of Turin (Italy). The results show that a simplified model can be powerful in evaluation of the energy demand and supply of buildings at urban scale. Moreover, the analogy between buildings and cooling fins allows to point out that the buildings shape is fundamental in the heat exchanges.
\end{abstract}

\section{INTRODUCTION}

Thermal energy demand represents over $30 \%$ of overall energy consumption; furthermore, energy consumption has increased and the growth rates are expected to continue, fueling the energy demand further. Increased energy consumption leads to more greenhouse gas (GHG) emissions with serious impacts on the global environment [1-2].

The dynamic simulation models represent a suitable tool to support the design of buildings from very preliminary phases. In fact, starting from specific inputs, such as weather conditions, construction technologies, materials, energy systems, operation settings, occupancy, and so forth, it is possible to estimate the realistic buildings energy performance. In particular, the simulation at neighborhood scale shows the multiple benefits deriving from using dynamic simulation tools at district level, for a more reliable investigation of building performance in the urban context [3].

Energy policies could be improved with the hourly models for an optimization of the energy distribution network, which is based on the morning peak of heat load. In addition, they can be used to evaluate how the different anthropic activities influence GHG emissions, for example, considering the impacts of building space heating with the traffic flows in different hours and climatic conditions [4].

Energy use of a building depends on aspects such as physical and thermal properties, climate, control and operational schemes, occupants' presence, and behavior and solar heat gains have large impact on the thermal balance of buildings [4-6]. Urban energy models consider these aspects and they are useful to study the building energy performance and to evaluate the thermal comfort, the architectural and building characteristics [7].

The aim of this paper is to suggest a simplified model to consider the energy balance and heat fluxes for buildings with hourly time steps for urban scale applications. Here, a Constructal law approach was developed in order to consider also an index for the buildings shape considering the fluxes of energy and the related convective phenomena [8]. The aim is to suggest a model useful to evaluate the global effect of the buildings energy consumptions in a district. The result is useful to produce evaluations on the energy requirement for heating districts. Last, a first evaluation of the buildings considered as cooling fins was introduced.

\section{STATE OF THE ART}

In the hourly thermal models, is crucial to understand which building characteristics result in high-energy losses.

Streicher et al. [9] developed a bottom-up model to simulate the national building energy demand for different energy retrofit scenarios, based on element specific data. In particular, they created a model based on detailed data on the building envelope and heating systems of over 25,000 Cantonal Building Energy Performance Certificates. They identified three building characteristics - rural typology, single-family houses and age of buildings - and evaluated the correlations with the final specific energy-use. Among buildings constructed before 1970, single-family houses (SFH) showed very high specific final energy-use for space heating (163-199 $\mathrm{kWh} / \mathrm{m}^{2}$ ) with approximately equal shares as multi-family houses (MFH) for the total aggregated final energy consumption. Buildings in suburban areas account for almost 
$50 \%$ of the total final energy-use. The buildings constructed before 1980 account for $70 \%$ of the national final energy-use for space heating, with buildings constructed before 1920 contributing for the $22 \%$. Most heat is lost through walls $(40 \%)$ followed by windows $(25 \%)$, roofs $(17 \%)$ and floors $(18 \%)$. Losses from walls are particular high $\left(73 \mathrm{kWh} / \mathrm{m}^{2}\right)$ for buildings constructed between 1920 and 1945 .

Verbekea and Audenaert [10] investigated some practical applications exploiting the effect of thermal inertia in design and operation of HVAC systems. They found that for most buildings and climates, higher amounts of thermal mass at the inner side of the thermal insulation appear to be beneficial with regard to improving thermal comfort and reducing the energy consumption. The exact contribution of thermal inertia was hard to ascertain, regarding impact on energy-use extreme figures ranging from $+10 \%$ to $-80 \%$ have been reported.

The analysis of building stock energy demand at the urban level needs both the characterization of building stock itself and the simulation of the energy demand of such buildings. For building geometry characterization, the integration of tools for digital image processing and GIS tools has been widely applied [11-12]. For example, Ali et al. [13] developed a methodology based on bottom-up approach for GIS-based residential building energy modelling at a district scale. The methodology was applied to districts in Dublin and the results indicated where and what type of buildings had the greatest potential for energy savings throughout the city. In particular, the main city area of Dublin had a low energy intensity per dwelling in comparison to the rest of the city. This is due to the fact that dwellings close to the center are relatively new or have been recently retrofitted (and around $52 \%$ buildings were constructed after 1990). Other areas show above average energy-use per dwelling because of older establishments. The variation in energy demand is significant across the two dwelling types, houses and apartments.

Different physical properties of the buildings can affect the heat gains through their envelope in different weather conditions. Hamanah et al. [14] presented a new residential thermal model that considers the internal heat gains and it can be used to evaluate accurately energy consumptions by simulation used to achieve thermal comfort conditions. Hourly daily, monthly, and annually energy consumptions and coefficient of performance (COP) were calculated, based on actual hourly outdoor temperature measurements and indoor generation heat for the year 2017, using the three thermal models and compared with the measurements.

Lundström et al. [6] created a space-heating model suitable for auto-generating baseline models of existing multifamily buildings. The proposed modelling framework consists of a thermal network, which is a lumped and simplified version of the UNI EN ISO 52016-1:2018 standard. This model was able to reproduce the hourly energy-use of space heating, indoor temperature, and operative temperature patterns obtained from the detailed building energy simulation software IDA ICE.

In previous research, Mutani et al. [4-5] analyzed the hourly heat load profile of residential and non-residential buildings of Turin considering the morning peak as a function of the outdoor air temperatures, the types of building and the solar exposure. They evaluated how the main variables on energy consumption can be used to describe yearly, monthly, daily or hourly energy-use in detail and how to improve energy planning with a spatial distribution. The results of the hourly heat load profile model shown that the percentage of the morning peak increases if the outside air temperature is higher and, at the same air temperature, for low energy performance buildings.

As already mentioned, the energy consumption of buildings depends on the dynamic interaction between the outdoor climate and the specific characteristics of the building's surrounding, the thermal characteristics of its envelope elements and technical systems. Dodoo et al. [15] conducted detailed simulations with a dynamic hour by hour energy balance model to investigate how combinations of different input parameters - connected to outdoor microclimate, building thermal envelope and household electrical equipment and technical installations - and assumptions affect the calculated energy demand of buildings. This analysis shows that household electricity use has significant impact on space heating demand of buildings.

This work starts from a model previously elaborated on a monthly basis also applied to an urban scale [16]. In this paper, a new indicator useful to evaluate the real behavior of the building in relation to a theoretical building will be introduced. To do so, a theoretical building composed of a homogeneous and isothermal parallelepiped with heat transfer only on its total border surface, base included, was considered.

This hourly model together with the use of GIS tool, allows geo-referencing information on the characteristics of buildings and on energy consumptions in order to optimize energy supply and demand at territorial scale. In this way it is possible to adapt energy policies to different built environments.

\section{MATERIALS AND METHODS}

The basic approach of urban building energy models with 'bottom-up' approach is to apply physical models of heat and mass flows in and around buildings to predict thermal energy use and the indoor and outdoor environmental conditions of buildings stocks. The UNI EN ISO 52016-1:2018 and UNI EN ISO 52017-1:2018 standards present a methodology for assessing the energy performance of buildings using equations for the transient heat and mass transfer between the external and internal environments through the opaque and transparent elements of the building envelope, as a function of internal and external heat flow, temperature and solar irradiation conditions. This method was used to calculate the time series of the internal temperature and the time interval is hourly. The internal temperature in a building was obtained using the sensible heat balance equation, Eqns. (1, 2, 3) assuming building temperature equal to the internal air temperature:

$$
\phi_{T}+\phi_{V}+\phi_{\text {extra }}-\left(\phi_{\mathrm{int}}+\phi_{s o l}\right)-\phi_{H}=C_{b} \cdot \frac{d T_{i, b}}{d t}
$$

$$
\begin{aligned}
& \sum U \cdot A \cdot\left(T_{e}-T_{i, a}\right)+\rho_{a} \cdot c_{a} \cdot \dot{V} \cdot\left(T_{e}-T_{i, a}\right)+ \\
& +F_{r} \cdot R_{s e} \cdot U_{o p} \cdot A_{o p} \cdot h_{r} \cdot\left(T_{e}-T_{s k y}\right)-\phi_{H}+ \\
& -\left(\phi_{\text {int }}+\alpha_{s o l} \cdot A_{o p, s o l} \cdot I+g_{w} \cdot A_{w, s o l} \cdot I\right)=C_{b} \cdot \frac{\left(T_{i, b}-T_{i, b-1}\right)}{3600}
\end{aligned}
$$




$$
\begin{aligned}
& T_{i, b}=\left(\sum U \cdot A+\rho_{a} \cdot c_{a} \cdot \frac{n \dot{V}}{3600}-\frac{C_{b}}{3600}\right)^{-1} \cdot \\
& \cdot\left[\sum\left(U \cdot A+\rho_{a} \cdot c_{a} \cdot \frac{n \dot{V}}{3600}\right) \cdot T_{e}+\right. \\
& +F_{r} \cdot R_{s e} \cdot U_{o p} \cdot A_{o p} \cdot h_{r} \cdot\left(T_{e}-T_{s k y}\right)+ \\
& \left.-\phi_{\mathrm{int}}-\left(\alpha_{\text {sol }} \cdot A_{o p, s o l}+g_{w} \cdot A_{w, s o l}\right) \cdot I-\phi_{H}-C_{b} \cdot \frac{T_{i, b-1}}{3600}\right]
\end{aligned}
$$

$F_{r}=F_{s h, o b} \cdot \frac{1-\cos (\gamma)}{2}=\frac{1+S V F_{g}}{2} \cdot \frac{1-\cos (\gamma)}{2}$

$A_{o p, s o l}=\xi \cdot A_{o p}$

$A_{w, s o l}=\xi \cdot A_{w}$

$\xi=\left\{\begin{array}{lll}\frac{\tan (\beta)}{H / W} & \text { if } & \beta<\arctan (H / W) \\ 1 & \text { if } & \beta \geq \arctan (H / W)\end{array}\right.$

where:

- $\phi_{\mathrm{T}}$ is the heat flow rate by transmission that depends on: thermal transmittances (U) of the building envelopes for different periods of construction, opaque and transparent heat dispersant areas (A) calculated with the GIS tool (with the transparent area equal to $1 / 8$ of the floor surface);

- $\phi_{\mathrm{V}}$ is the heat flow rate by ventilation that depends on: the heat capacity of air per volume $\left(\rho_{\mathrm{a}} \cdot \mathrm{c}_{\mathrm{a}}=1,200 \mathrm{~J} / \mathrm{m}^{3} / \mathrm{K}\right)$ and the hourly volumes of air exchanges $(\mathrm{nV})$; it was assumed that the ventilation heat losses are minimal in the night-time due to the occupant behavior (with hourly profiles of internal heat gains from occupants and equipment for residential buildings in UNI/TS 11300-1:2014).

- $\phi_{\text {extra }}$ is extra heat flow rate by thermal radiation to the sky that depends on: the form factor between the buildings and the sky (Fr), the external thermal surface resistance $\left(\mathrm{R}_{\mathrm{se}}\right)$, the radiative heat transfer coefficient $\left(h_{r}\right)$, the thermal transmittance of opaque envelope and its area ( $\mathrm{U}_{\mathrm{op}}$ and $\left.\mathrm{A}_{\mathrm{op}}\right)$, and the sky temperatures $\left(\mathrm{T}_{\text {sky }}\right)$; in particular, Fr (Equation 4$)$ is the shading reduction factor for the external obstructions $\left(\mathrm{F}_{\mathrm{sh}, \mathrm{ob}}\right)$ and it was calculated measuring the sky view factor at ground level $\left(\mathrm{SVF}_{\mathrm{g}}\right)$, the average SVF of buildings, the solar height $\beta$ and the angle of urban canyons $\arctan (\mathrm{H} / \mathrm{W})$.

- $\phi_{\text {int }}$ is the heat flow rate due to internal heat sources that depends on: the floor area of residential buildings and the average floor area per dwelling; the internal heat gains were calculated using the hourly profiles of internal heat gains from occupants and equipment for residential buildings in UNI/TS 11300-1:2014.

- $\phi_{\text {sol }}$ is the heat flow rate due to solar heat gains that depends on: absorption coefficient of the opaque envelope $\left(\alpha_{\text {sol,op }}\right.$ assumed equal to 0.6 considering an average colour of buildings walls), the area of the opaque envelope $\left(\mathrm{A}_{\mathrm{op}}\right)$, the effective glazing area $\left(\mathrm{A}_{\mathrm{sol}, \mathrm{w}}\right)$, the solar energy transmittance of the glasses $\left(g_{w}\right)$, and the incident solar irradiance (I) calculated considering the orientation and inclination of the building envelope surfaces;

- $\phi_{\mathrm{H}}$ is the heat flow released by the heating system to the confined environments to guarantee a comfortable air temperature (i.e. $20{ }^{\circ} \mathrm{C}$ in the heating season); it can be calculated multiplying the energy supplied to the heating system for the system efficiency $\eta_{\mathrm{H}}[17]$;

- $\mathrm{T}_{\mathrm{e}}$ is the external air temperature, $\mathrm{T}_{\mathrm{i}, \mathrm{a}}$ is the internal air temperature, $\mathrm{T}_{\mathrm{i}, \mathrm{b}}$ is the internal building temperature at different hours of the day, $\mathrm{C}_{\mathrm{b}}$ is the internal effective heat capacity of the buildings calculated using the UNI/TS 11300-1:2014 and UNI EN ISO 52016-1:2018 standards; for the hourly internal temperature, it has been defined that the $\mathrm{T}_{\mathrm{i}, \mathrm{b}}$ can vary from 18 to $22{ }^{\circ} \mathrm{C}$ during the day (from 8 a.m. to 10 p.m.) and decrease up to $16^{\circ} \mathrm{C}$ during the night.

- I is the incident solar irradiance, $\xi$ defines the percentage of sunny surfaces as a function of the height of the sun $(\beta)$ and of the urban canyon height to distance ratio $\mathrm{H} / \mathrm{W}$. When the solar height $\beta$ is minor than the angle of urban canyons $\arctan (\mathrm{H} / \mathrm{W})$, the shadow quota is equal to the ratio between $\tan (\beta)$ and $\mathrm{H} / \mathrm{W}$; while the $\arctan (\mathrm{H} / \mathrm{W})$ is greater/equal to 1 there is no shadow on the buildings walls Eq. (5).

In the second part of this work, the buildings have been supposed as homogeneous and isothermal parallelepipeds with heat transfer only on their total border surface, bases included. The heat transfer of these theoretical buildings, can be obtained by the heat power exchanged by cooling fins without any internal temperature gradient:

$\phi_{\text {fin }}=\lambda \cdot \sqrt{\frac{h_{c} \cdot P}{\lambda \cdot A}} \cdot A \cdot\left(T_{S}-T_{a}\right) \cdot \frac{\frac{h}{\lambda} \cdot \sqrt{\frac{\lambda \cdot A}{h_{c} \cdot P}}+\tanh \left(\sqrt{\frac{\lambda \cdot A}{h_{c} \cdot P}} \cdot L\right)}{1+\frac{h}{\lambda} \cdot \sqrt{\frac{\lambda \cdot A}{h_{C} \cdot P} \cdot \tanh \left(\sqrt{\frac{\lambda \cdot A}{h_{C} \cdot P}} \cdot L\right)}}$

where: $\lambda$ is the constant of heat conduction, $h_{c}$ is the constant of heat convection (that depends by the wind velocity according to UNI ISO 6946:2018), A is the exchange area, T is the temperature, $\mathrm{P}$ is the perimeter of the transversal section of the building and the subscript $\mathrm{S}$ means building surface and a means external environment.

An indicator for the building inefficiency can be introduced:

$\chi=\frac{\phi_{\text {fin }}}{\phi_{\text {real }}}$

which represents the ratio between the heat flux of the fin (with only heat transmission) and the heat flux of the real building (with also its thermal inertia); lower is this value, more sustainable is the building.

\section{CASE STUDY}

The city of Turin, in Piedmont Region, is located in Northwester part of the Italy. In Turin there are about 60,000 heated buildings and the residential sector has about 45,000 buildings (with a heated gross volume of $232 \mathrm{Mm}^{3}$ ). The residential sector has principally large and compact condominiums with surface to volume ratio (S/V) less than $0.45 \mathrm{~m}^{-1}$ for more than 24,000 (with an average value of 0.55 $\mathrm{m}^{-1}$ ). Considering the period of construction, the $57 \%$ of the buildings were built before 1960, the $80 \%$ of the buildings before 1970 (before the first Italian Law on energy savings for buildings), the residential buildings built in 1970-2000 are about $15 \%$ and after 2006 only $2 \%$.

This study analyses residential buildings connected to the district heating network (DHN) in Turin, with a continental 
temperate climate and 2,648 heating degree days (HDD) at $20{ }^{\circ} \mathrm{C}$ (UNI 10349-3:2016). In a central district of the city of Turin, the annual space heating consumption of about 90 buildings and the hourly climate data of the weather station of Politecnico di Torino were known [16-17]. Of those 90 buildings, for 50 residential buildings also the hourly consumption data were given for two consecutive heating seasons. These residential buildings are big condominiums with average value of $\mathrm{S} / \mathrm{V}$ equal to $0.30 \mathrm{~m}^{-1}$ and were built before 1970; particularly, 17 buildings were built between 1919 and 1945, 20 in 1946-1960, 11 in 1961-1970 and only 2 between 1971 and 1980 .

With the support of a GIS tool (ArcGIS 10.6), a database was created with the following information (input data):

- the hourly energy consumption of 50 residential buildings and annual consumption for 90 buildings for at least two consecutive heating seasons (2012-13 and 2013-14) [4, 16, $18]$;

- the Sky View Factor (SVF) for the built environment, obtained through the use of Relief Visualization Toolbox [11] using the Digital Surface Model (DSM) of Turin with a precision of 5 meters;

- the hourly climate data of the Politecnico weather station: air temperature and sky temperature $\left[{ }^{\circ} \mathrm{C}\right]$, relative humidity [\%], solar irradiance on horizontal plane $\left(\mathrm{I}_{\text {hor }}\right)$, wind direction $\left[{ }^{\circ}\right]$, and wind velocity $[\mathrm{m} / \mathrm{s}]$; also the climate data of ARPA Piemonte weather stations in Turin can be used (https://www.arpa.piemonte.gov.it/);

- the quota of sunny surfaces at different hours of the day considering as reference the typical monthly day [19]; this quota was calculated using the hourly variation of shadows percentage for each building Eq. (4) considering: the height of the sun $\beta$ (solar position), the shadow created by the different buildings which is influenced by their height $\mathrm{H}$ and distance $\mathrm{W}$;

- the constructive characteristics of building as period of construction and type of users, geometric characteristics of buildings such as height, perimeter, heat surface, net/gross volume, surface to volume ratio $(\mathrm{S} / \mathrm{V})$ were calculated with the Municipal Technical Map of Turin (2015) and BDTRE of Piedmont Region (2018);
- thermal characteristics of building: thermal transmittances (U) distinguished by the period of construction of buildings, total solar transmittance $\left(\mathrm{g}_{\mathrm{w}}\right)$ of the transparent envelope, absorption coefficient for solar radiation $\left(\alpha_{\text {sol }}\right)$ of opaque envelope components, emissivity $(\varepsilon)$ of the envelope, and thermal capacity $\left(\mathrm{C}_{\mathrm{b}}\right)$ (UNI/TS 11300-1:2014, UNI EN ISO 52016-1:2018, UNI-TR 11552:2014);

- the census section database: occupancy, percentage of heated volume, level of maintenance of buildings, type of energy vectors, individual or central heating systems (census data: ISTAT 2011);

- the urban variables calculated with the use of Municipal Technical Map, that describes the characteristics of the selected urban area: canyon effect (H/W), building density (BD), building coverage ratio (BCR), and main orientation of streets (MOS);

- type of outdoor surfaces, identified with satellite images (Landsat 7 and 8): albedo or reflection coefficient of solar radiation $\left(\mathrm{a}_{\mathrm{NIR}}\right)$ and presence of vegetation (NDVI).

In Table 1 are indicated the climate characteristics of Turin registered by the weather station of Politecnico di Torino. Average values of the external air temperature $(\mathrm{T})$, the average daily solar irradiance on horizontal plane $\left(\mathrm{I}_{\mathrm{hor}}\right)$ and wind velocity (v) are shown for each month considering the heating season 2012/2013.

Table 1. Climate variables for the heating season 2012/2013 in Turin (IT)

\begin{tabular}{cccccccc}
\hline Month & \multicolumn{7}{c}{ Oct-12Nov-12Dec-12Jan-13Feb-13Mar-13Apr-13 } \\
\hline$T\left[{ }^{\circ} \mathrm{C}\right]$ & 15.5 & 10.6 & 4.6 & 5.0 & 4.3 & 8.2 & 13.9 \\
\hline Ihor $\left[\mathrm{Wh} / \mathrm{m}^{2}\right]$ & 3.2 & 2.2 & 1.8 & 1.9 & 3.0 & 3.7 & 4.8 \\
\hline$v[\mathrm{~m} / \mathrm{s}]$ & 1.25 & 1.26 & 1.28 & 1.22 & 1.44 & 1.73 & 1.61 \\
\hline
\end{tabular}

Table 2 shows the thermal and constructive characteristics of the 50 buildings. As already mentioned, the main period of construction is before 1970 with higher values of thermal transmittance of opaque envelope $\left(\mathrm{U}_{\mathrm{op}}\right)$ and of windows $\left(\mathrm{U}_{\mathrm{w}}\right)$. In addition, the shape is very similar, therefore there are mainly large and compact condominiums (the average value of $\mathrm{S} / \mathrm{V}$ is $0.302 \mathrm{~m}^{-1}$ ).

Table 2. Thermal and constructive characteristics of analyzed building for different periods of construction

\begin{tabular}{|c|c|c|c|c|c|}
\hline Period of construction & n. buildings & $S / V_{(\text {avg })}\left[\mathrm{m}^{-1}\right]$ & $\boldsymbol{S} / \boldsymbol{V}\left[\mathrm{m}^{-1}\right]$ & $\boldsymbol{U}_{\boldsymbol{o p}}\left[\mathrm{Wm}^{-2} \mathrm{~K}^{-1}\right]$ & $\boldsymbol{U}_{\boldsymbol{w}}\left[\mathrm{Wm}^{-2} \mathrm{~K}^{-1}\right]$ \\
\hline $1919-1945$ & 17 & 0.316 & $0.28-0.39$ & 0.99 & \multirow{5}{*}{$3.0-5.9$} \\
\hline $1946-1960$ & 20 & 0.294 & $0.26-0.34$ & 1.04 & \\
\hline $1961-1970$ & 11 & 0.296 & $0.26-0.41$ & 1.04 & \\
\hline $1971-1980$ & 2 & 0.310 & $0.29-0.33$ & 1.02 & \\
\hline Total / avg. & 50 & 0.302 & $0.26-0.41$ & 1.03 & \\
\hline
\end{tabular}

Table 3. Characteristics of selected residential buildings: building orientation (BO), period of construction, geometrical characteristics (net heated volume $\mathrm{V}_{\mathrm{n}}$, surface to volume ratio $\mathrm{S} / \mathrm{V}$, height $\mathrm{H}$ ), urban variables (average distance between buildings $\mathrm{W}$, canyon effect $\mathrm{H} / \mathrm{W}$, sky view factor at ground level $\left(\mathrm{SVF}_{\mathrm{g}}\right)$ and the buildings maintenance level (from $1=\mathrm{low}$ to 4=optimal)

\begin{tabular}{cccccccccc}
\hline $\boldsymbol{I D}_{\boldsymbol{b}}$ & BO & Period & $\boldsymbol{V} \boldsymbol{n}\left[\mathrm{m}^{3}\right]$ & $\boldsymbol{S} / \boldsymbol{V}\left[\mathrm{m}^{-1}\right]$ & $\boldsymbol{H}[\mathrm{m}]$ & $\boldsymbol{W}[\mathrm{m}]$ & $\boldsymbol{H} / \boldsymbol{W}[-]$ & $\boldsymbol{S} \boldsymbol{V} \boldsymbol{F}_{\boldsymbol{g}}[-]$ & Maint. Level \\
\hline 47 & $\mathrm{~S} / \mathrm{E}$ & $1919-45$ & 2728 & 0.42 & 18.4 & 28.12 & 0.503 & 0.484 & 3 \\
\hline 30 & $\mathrm{~S} / \mathrm{E}$ & $1919-45$ & 2195 & 0.39 & 18.5 & 26.46 & 0.500 & 0.242 & 3 \\
\hline 88 & $\mathrm{~S} / \mathrm{O}$ & $1919-45$ & 3147 & 0.41 & 14.7 & 23.69 & 0.538 & 0.282 & 4 \\
\hline 77 & $\mathrm{~S} / \mathrm{O}$ & $1919-45$ & 5105 & 0.34 & 22.1 & 22.77 & 0.589 & 0.253 & 3 \\
\hline 87 & $\mathrm{~S} / \mathrm{O}$ & $1919-45$ & 3118 & 0.40 & 15.1 & 23.69 & 0.538 & 0.282 & 4 \\
\hline 20 & $\mathrm{~S} / \mathrm{E}$ & $1946-60$ & 2800 & 0.36 & 22.8 & 28.25 & 0.550 & 0.396 & 3 \\
\hline 37 & $\mathrm{~S} / \mathrm{E}$ & $1946-60$ & 2280 & 0.38 & 19.5 & 24.07 & 0.522 & 0.301 & 3 \\
\hline 5 & $\mathrm{~S} / \mathrm{E}$ & $1946-60$ & 2010 & 0.38 & 25.0 & 22.63 & 0.493 & 0.251 & 4 \\
\hline
\end{tabular}




\begin{tabular}{llllllllll}
\hline 13 & S/E & $1946-60$ & 3232 & 0.35 & 19.6 & 24.07 & 0.522 & 0.301 & 3 \\
\hline 62 & S/O & $1946-60$ & 6525 & 0.34 & 21.9 & 21.71 & 0.569 & 0.243 & 3 \\
\hline 41 & S/O & $1946-60$ & 2265 & 0.41 & 23.7 & 28.25 & 0.550 & 0.396 & 3 \\
\hline 46 & S/E & $1961-70$ & 3100 & 0.56 & 20.2 & 22.77 & 0.589 & 0.253 & 3 \\
\hline 79 & S/E & $1961-70$ & 4542 & 0.34 & 18.7 & 26.46 & 0.500 & 0.242 & 3 \\
\hline 61 & S/O & $1961-70$ & 9957 & 0.32 & 22.5 & 21.71 & 0.569 & 0.243 & 3 \\
\hline 44 & S/O & $1961-70$ & 2405 & 0.38 & 18.9 & 17.51 & 0.568 & 0.253 & 3 \\
\hline 76 & S/O & $1961-70$ & 2049 & 0.37 & 23.0 & 28.25 & 0.550 & 0.396 & 3 \\
\hline
\end{tabular}

Figure 1 shows the case study area, in which are localized the case study of 50 users (residential buildings). It is possible to observe that the morphological characteristics of the block of buildings are very similar with courtyard buildings with about 5 floors on a regular orthogonal grid typical of Roman cities.

Starting from the hourly thermal consumptions data of 50 residential buildings, 16 buildings were selected considering the period of construction, the orientation, the characteristics of urban context and the type of adjacent street; for example, the buildings located in front of the large tree-lined avenues were not selected because the space heating energy consumptions can be influenced by this position.

Table 3 shows the main characteristics of the 16 residential buildings selected. For these buildings the shape is similar, the height is between 15 and 25 meters, the H/W factor is closed to 0.5 , the $\mathrm{SVF}_{\mathrm{g}}$ at ground level is the most variable, with values from 0.24 to 0.48 , and the maintenance level is constant (only three buildings have an optimal level, the others have good level). For each building an SVF was calculated as the average between the value at the ground floor $\mathrm{SVF}_{\mathrm{g}}$ and the value at the roof level considered equal to 1 .

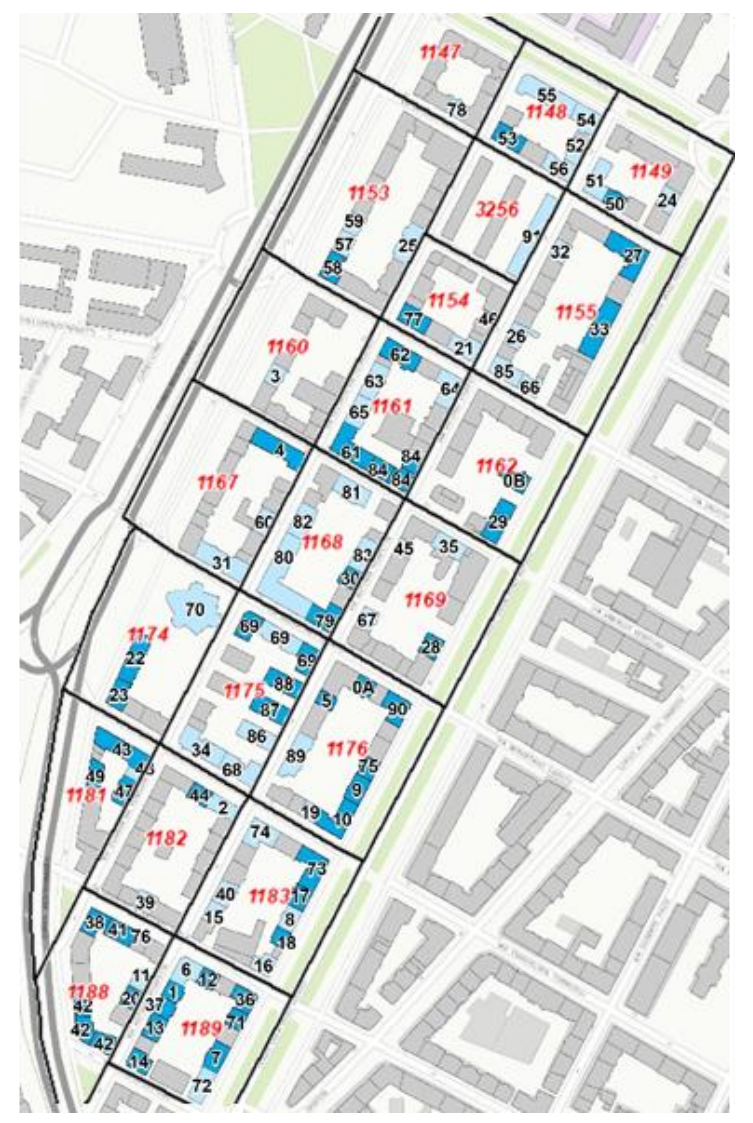

Figure 1. Case study in a central district of Turin (Italy): buildings $\left(\mathrm{ID}_{\mathrm{b}}\right)$ with annual space heating consumptions are indicated in blue, with hourly consumptions in light blue; the $\mathrm{ID}_{\mathrm{cs}}$ of census sections is in red
As mentioned before, also the urban variables affect the thermal energy consumption of buildings; in Table 4 are reported the values of the main urban variables at census section scale. In particular, 9 census sections in which there are the 16 selected buildings (Table 4) are highlighted in yellow. The building coverage ratio (BCR) values are between 0.4 and 0.5 with the exception of section '1181' (BCR is 0.25 ); the building density (BD) is more variable, since it depends on the height of the building, but in the 9 selected census sections the values are very similar and close to the average $\left(\mathrm{BD}_{\text {avg }}\right.$ is $\left.6.84 \mathrm{~m}^{3} / \mathrm{m}^{2}\right)$. The canyon height to width ratio $(\mathrm{H} / \mathrm{W})$ is homogeneous for all selected areas with values close to 0.5 and the main orientation of streets is East-South (typical of Turin) with $\mathrm{MOS}_{\text {avg }}$ of 0.6 , except for the section '1154' (MOS=1 for the East-West axis and MOS $=0$ for the North-South axis). The $\mathrm{SVF}_{\mathrm{g}}$ at ground level is quite variable and also the average SVF, and finally the non-presence of vegetation (NDVI) e the low reflectance of outdoor surfaces is uniform and typical of an urban built environment.

Table 4. Characteristics of urban variables: the census sections in which there are the 16 buildings selected for analysis are highlighted in yellow

\begin{tabular}{ccccccccc}
\hline $\boldsymbol{I D}_{\boldsymbol{c s}}$ & $\boldsymbol{B C R}$ & $\boldsymbol{B D}$ & $\boldsymbol{H} / \boldsymbol{W}$ & $\boldsymbol{M O S}$ & $\boldsymbol{S} \boldsymbol{V} \boldsymbol{F}_{\boldsymbol{g}}$ & $\boldsymbol{S} \boldsymbol{V} \boldsymbol{F}$ & $\boldsymbol{N D V I}$ & $\boldsymbol{a}_{\boldsymbol{N I R}}$ \\
\hline 1147 & 0.26 & 5.44 & 0.58 & 0.63 & 0.49 & 0.75 & 0.08 & 0.09 \\
\hline 1148 & 0.43 & 11.11 & 0.69 & 0.62 & 0.33 & 0.67 & 0.09 & 0.09 \\
\hline 1149 & 0.31 & 7.56 & 0.53 & 0.29 & 0.31 & 0.66 & 0.16 & 0.09 \\
\hline 1153 & 0.36 & 7.24 & 0.56 & 0.63 & 0.49 & 0.75 & 0.08 & 0.10 \\
\hline 1154 & 0.47 & 7.21 & 0.59 & 0.30 & 0.25 & 0.63 & 0.05 & 0.10 \\
\hline 1155 & 0.41 & 6.59 & 0.55 & 0.62 & 0.27 & 0.64 & 0.15 & 0.11 \\
\hline 1160 & 0.35 & 4.82 & 0.52 & 0.63 & 0.33 & 0.67 & 0.09 & 0.10 \\
\hline 1161 & 0.56 & 9.13 & 0.57 & 0.63 & 0.24 & 0.62 & 0.05 & 0.10 \\
\hline 1162 & 0.37 & 5.52 & 0.49 & 0.62 & 0.28 & 0.64 & 0.17 & 0.11 \\
\hline 1167 & 0.35 & 6.33 & 0.58 & 0.63 & 0.41 & 0.71 & 0.11 & 0.10 \\
\hline 1168 & 0.51 & 8.49 & 0.50 & 0.62 & 0.24 & 0.62 & 0.05 & 0.09 \\
\hline 1169 & 0.44 & 7.68 & 0.55 & 0.62 & 0.25 & 0.63 & 0.16 & 0.11 \\
\hline 1174 & 0.32 & 3.64 & 0.37 & 0.63 & 0.56 & 0.78 & 0.10 & 0.10 \\
\hline 1175 & 0.49 & 7.96 & 0.54 & 0.63 & 0.28 & 0.64 & 0.04 & 0.10 \\
\hline 1176 & 0.39 & 6.20 & 0.49 & 0.62 & 0.25 & 0.63 & 0.13 & 0.10 \\
\hline 1181 & 0.25 & 5.26 & 0.50 & 0.63 & 0.48 & 0.74 & 0.11 & 0.11 \\
\hline 1182 & 0.56 & 6.89 & 0.57 & 0.63 & 0.25 & 0.63 & 0.04 & 0.10 \\
\hline 1183 & 0.40 & 6.75 & 0.57 & 0.62 & 0.31 & 0.66 & 0.13 & 0.10 \\
\hline 1188 & 0.36 & 7.79 & 0.55 & 0.62 & 0.40 & 0.70 & 0.10 & 0.11 \\
\hline 1189 & 0.39 & 7.05 & 0.52 & 0.62 & 0.30 & 0.65 & 0.14 & 0.11 \\
\hline 3256 & 0.32 & 4.98 & 0.53 & 0.63 & 0.26 & 0.63 & 0.07 & 0.10 \\
\hline avg. & $\mathbf{0 . 3 9}$ & $\mathbf{6 . 8 4}$ & $\mathbf{0 . 5 4}$ & $\mathbf{0 . 5 9}$ & $\mathbf{0 . 3 3}$ & $\mathbf{0 . 6 7}$ & $\mathbf{0 . 1 0}$ & $\boldsymbol{0 . 1 0}$ \\
\hline st.dv. & $\mathbf{0 . 0 9}$ & $\mathbf{1 . 6 5}$ & $\mathbf{0 . 0 6}$ & $\mathbf{0 . 1 0}$ & $\mathbf{0 . 1 0}$ & $\mathbf{0 . 0 5}$ & $\mathbf{0 . 0 4}$ & $\mathbf{0 . 0 1}$ \\
\hline & & & & & & & &
\end{tabular}

\section{RESULTS}

This work introduces a bottom-up modelling hourly energy balance of residential buildings for a central district in the city of Turin. The selected area has very similar geometrical, morphological and microclimate characteristics (see Table 4). The only variable in changing is the Sky View Factor and the 
solar exposition of the buildings block (see Figure 2). The sky view factor has been calculated for each block of buildings with an average value between the $\mathrm{SVF}_{\mathrm{g}}$ and the unitary value, considered on the roof.

In Figure 3 an example of hourly data for the building $\mathrm{ID}_{\mathrm{b}}$ 62 is presented for typical days during the heating season 2012/2013. Data of space heating energy consumptions have been calculated on hourly time step with the use of MathLab trying to eliminate any anomalies and selecting only the buildings that had continuous consumption data.

The bottom up model has been realized with an Excel calculator sheet considering an average annual value of the heating system efficiency (about 0.7-0.8 for the buildings connected to the district heating network). Figure 4 shows the results of the model for the building $\mathrm{ID}_{\mathrm{b}} 62$ with a heating system efficiency of 0.73 . Excluding the months of October and April in which the times for switching the system on and off can cause anomalies in the consumption data, the monthly results of energy consumption have a percentage error lower than $15 \%$ with an annual percentage error less than $5 \%$.

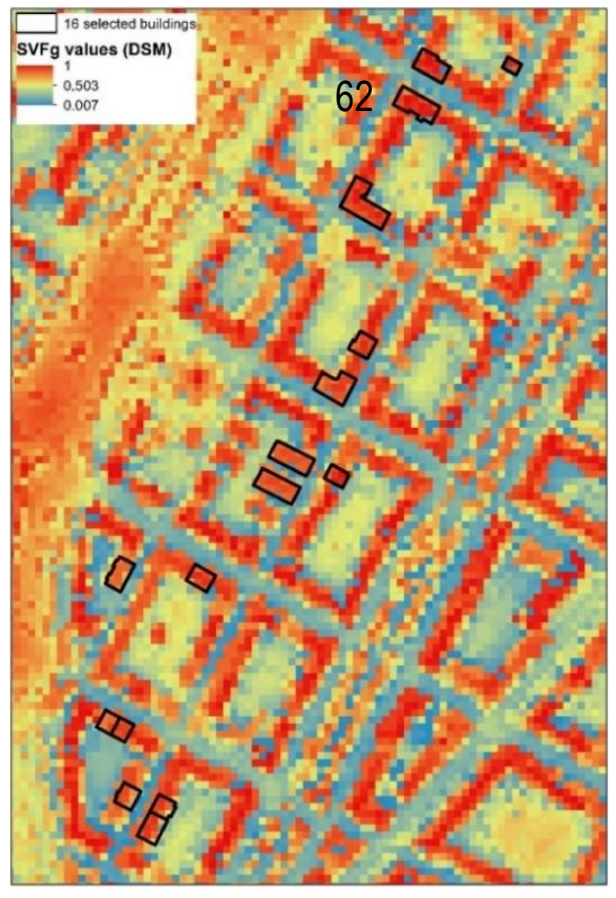

Figure 2. Sky view factor $\left(\mathrm{SVF}_{\mathrm{g}}\right)$ at ground level calculated with the use of GIS tool and Relief Visualization Toolbox [11]; the 16 residential buildings selected for the analysis are represented in black

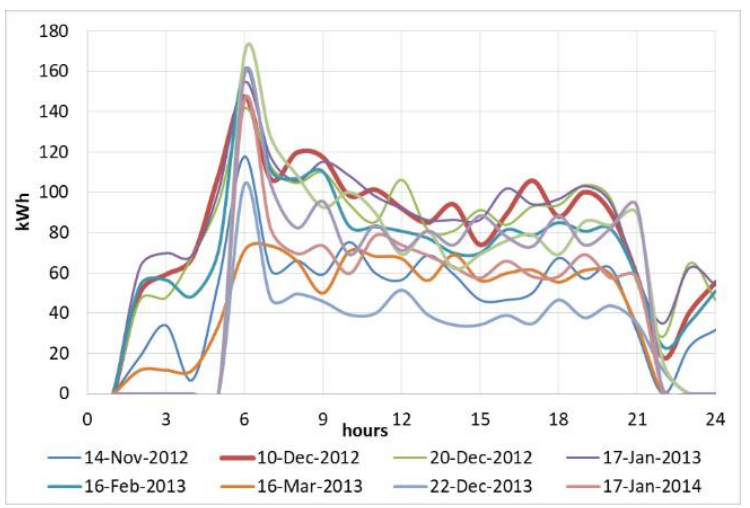

Figure 3. Daily energy consumption for space heating (for $\left.\mathrm{ID}_{\mathrm{b}} 62\right)$

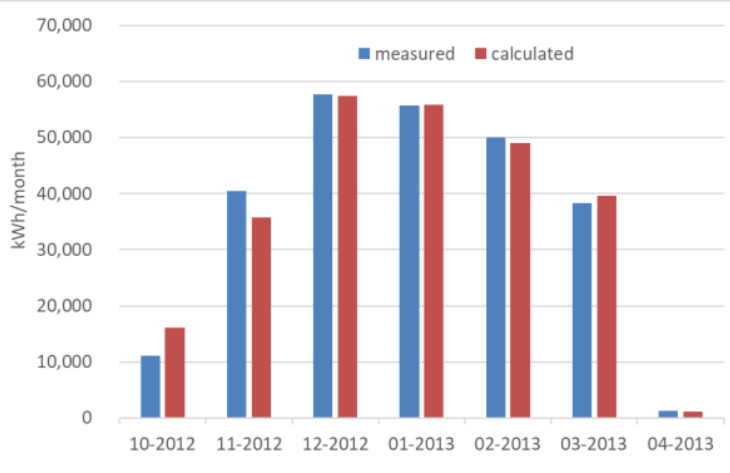

Figure 4. Monthly energy consumption for space heating of building $\mathrm{ID}_{\mathrm{b}} 62$ in the heating season 2012-13; in April the heating system was turned on only one day

Table 5. Characteristics of the theoretical cooling fins associated to the case study buildings

\begin{tabular}{cccccccc}
\hline $\boldsymbol{I D}_{\boldsymbol{b}}$ & $\begin{array}{c}\boldsymbol{A} \\
{\left[\mathrm{m}^{2}\right]}\end{array}$ & $\begin{array}{c}\boldsymbol{P} \\
{[\mathrm{m}]}\end{array}$ & $\begin{array}{c}\boldsymbol{H} \\
{[\mathrm{m}]}\end{array}$ & $\begin{array}{c}\boldsymbol{V} \\
{\left[\mathrm{m}^{3}\right]}\end{array}$ & $\begin{array}{c}\boldsymbol{S} \boldsymbol{d} \\
{\left[\mathrm{m}^{2}\right]}\end{array}$ & $\begin{array}{c}\boldsymbol{P} \\
{[\mathrm{m}]}\end{array}$ & $\begin{array}{c}\boldsymbol{\lambda} \\
{[\mathrm{W} / \mathrm{m} / \mathrm{K}]}\end{array}$ \\
\hline 47 & 262 & 70 & 18.35 & 4804 & 1583.7 & 63.48 & 0.82 \\
\hline 30 & 204 & 59 & 18.52 & 3773 & 1029.4 & 38.0 & 0.68 \\
\hline 88 & 373 & 84 & 14.71 & 5484 & 1982.2 & 94.2 & 1.08 \\
\hline 77 & 316 & 75 & 22.14 & 6986 & 1810.7 & 59.0 & 1.14 \\
\hline 87 & 389 & 85 & 15.10 & 5871 & 2062.3 & 95.4 & 0.74 \\
\hline 20 & 199 & 58 & 22.77 & 4538 & 1153.4 & 36.7 & 0.54 \\
\hline 37 & 185 & 56 & 19.5 & 3600 & 954.3 & 33.79 & 0.72 \\
\hline 5 & 150 & 50 & 24.98 & 3743 & 1027 & 31.49 & 0.79 \\
\hline 13 & 260 & 65 & 19.6 & 5094 & 1316 & 45.9 & 0.98 \\
\hline 62 & 405 & 93 & 21.89 & 8871 & 2383 & 79.3 & 1.12 \\
\hline 41 & 148 & 49 & 23.72 & 3522 & 945.3 & 29.8 & 1.19 \\
\hline 46 & 89 & 38 & 20.2 & - & 688.32 & 27.0 & 0.82 \\
\hline 79 & 387 & 86 & 18.68 & 7234 & 1917.3 & 69.5 & 0.96 \\
\hline 61 & 542 & 117 & 22.55 & 12232 & 3233.0 & 104.9 & 0.76 \\
\hline 44 & 205 & 58 & 18.92 & 3869 & 1064 & 39.0 & 0.72 \\
\hline 76 & 148 & 49 & 23.02 & 3409 & 804.6 & 24.7 & 0.74 \\
\hline
\end{tabular}

Table 6. Building characteristics and energy consumption data for the day of December $20^{\text {th }} 2012$ with an average outdoor air temperature of $3.9^{\circ} \mathrm{C}$ (* for building 41

December $21^{\text {st }} 2012$ with $3.7^{\circ} \mathrm{C}$ was used)

\begin{tabular}{ccccccc}
\hline ID & BO & Period & $\begin{array}{c}\text { Maint. } \\
\text { Level }\end{array}$ & $\begin{array}{c}\text { Bn } \\
{\left[\mathrm{m}^{3}\right]}\end{array}$ & $\begin{array}{c}\text { Building energy } \\
\text { density on Dec } \\
\mathbf{2 0}^{\text {th }} \\
{\left[\mathrm{kWh} / \mathrm{d} / \mathrm{m}^{3}\right]}\end{array}$ & $\begin{array}{c}\boldsymbol{\chi} \\
{[-]}\end{array}$ \\
\hline 47 & $\mathrm{~S} / \mathrm{E}$ & $1919-45$ & 3 & 2728 & 303.92 & 0.33 \\
\hline 30 & $\mathrm{~S} / \mathrm{E}$ & $1919-45$ & 3 & 2195 & 221.43 & 0.18 \\
\hline 88 & $\mathrm{~S} / \mathrm{O}$ & $1919-45$ & 4 & 3147 & 248.30 & 0.50 \\
\hline 77 & $\mathrm{~S} / \mathrm{O}$ & $1919-45$ & 3 & 5105 & 305.90 & 0.15 \\
\hline 87 & $\mathrm{~S} / \mathrm{O}$ & $1919-45$ & 4 & 3118 & 277.45 & 0.20 \\
\hline 20 & $\mathrm{~S} / \mathrm{E}$ & $1946-60$ & 3 & 2800 & 237.54 & 0.09 \\
\hline 37 & $\mathrm{~S} / \mathrm{E}$ & $1946-60$ & 3 & 2280 & 282.30 & 0.28 \\
\hline 5 & $\mathrm{~S} / \mathrm{E}$ & $1946-60$ & 4 & 2010 & 406.67 & 0.43 \\
\hline 13 & $\mathrm{~S} / \mathrm{E}$ & $1946-60$ & 3 & 3232 & 192.11 & 0.40 \\
\hline 62 & $\mathrm{~S} / \mathrm{O}$ & $1946-60$ & 3 & 6525 & 295.82 & 0.13 \\
\hline 41 & $\mathrm{~S} / \mathrm{O}$ & $1946-60$ & 3 & 2265 & $207.92 *$ & $0.16^{*}$ \\
\hline 46 & $\mathrm{~S} / \mathrm{E}$ & $1961-70$ & 3 & 3100 & 163.90 & 0.13 \\
\hline 79 & $\mathrm{~S} / \mathrm{E}$ & $1961-70$ & 3 & 4542 & 202.51 & 0.23 \\
\hline 61 & $\mathrm{~S} / \mathrm{O}$ & $1961-70$ & 3 & 9957 & 259.25 & 0.07 \\
\hline 44 & $\mathrm{~S} / \mathrm{O}$ & $1961-70$ & 3 & 2405 & 278.96 & 0.13 \\
\hline 76 & $\mathrm{~S} / \mathrm{O}$ & $1961-70$ & 3 & 2049 & 304.20 & 0.11 \\
\hline & & & & & &
\end{tabular}


In Tables 5 and 6 the data used for the analogy with the cooling fins are summarized with the indicator of inefficiency $\chi$. In Table 5 are reported the principal geometrical characteristics as the building perimeter $\mathrm{P}$ and the used dispersant perimeter P' used in the cooling fins analogy. The conductivity $\lambda$ is an equivalent value calculated considering the thermal transmittance of the envelope and its thickness.

In Table 5, it can be observed that the inefficiency $\chi$ is always less than 1 , due to the effects of the other heat transfer components characterizing building behaviour as the internal and solar heat gains and the thermal inertia of the structures.

\section{CONCLUSIONS}

Nowadays, in industrialized countries, the management of GHG emissions represents one of the present compelling issue. The improvement of the energy efficiency and a more rational use of energy can be considered a fundamental economic strategy for the sustainable development of the industrialized countries. In particular, the building thermal management can represent a fundamental aspect of the reduction of GHG emissions because there is still room for improvement.

So, this paper suggests to introduce the analysis of the energy inefficiency, just developed for the industrial and social processes in Refs. [20-21], to the building thermal modelling.

To do so, some new indicators were introduced able to express the inefficiency of the thermal transfer in building, in relation to a theoretical equivalent model for each building. This indicator is related to the fluxes of energy and it is based on a Constructal law approach to energy system. Indeed, the results point out how the shape of the buildings represents a fundamental quantity to be considered in the heat transfer. Lower is building inefficiency, better is the energy efficiency level of the building itself.

From the numerical results obtained from this first case study, we can point out that the shape of the building is fundamental in its heat exchange; indeed, the building inefficiency is higher for the buildings with:

- high values of the dispersing perimeter P';

- high surface to volume ratio S/V;

- high values of thermal conductivity $\lambda$;

- high values of sky view factor SVF;

- low values of height to distance ratio H/W.

The novelty of the presented model consists in the use of few variables for the application of the space heating energy model at territorial scale with the support of GIS tool.

This paper represents a first step in the simplification of the heat fluxes analysis for energy saving considerations and future sustainable urban planning. Data retrieval work is already underway to optimize the energy consumption hourly model at urban scale, for example by differentiating the different components of solar radiation. Furthermore, it is necessary above all to test the model in different urban contexts because the case study was very homogeneous both in terms of the shape of the buildings and the presence of greenery and type of roads.

\section{REFERENCES}

[1] Harish VSKV, Kumar A. (2016). A review on modelling and simulation of building energy systems. Renewable and Sustainable Energy Reviews 56: 1272-1292. http://dx.doi.org/10.1016/j.rser.2015.12.040

[2] Nageler P, Koch A, Mauthner F, Leusbrock I, Mach T, Hochenauer C, Heimrath R. (2018). Comparison of dynamic urban building energy models (UBEM): Sigmoid energy signature and physical modelling approach. Energy \& Buildings 179: 333-343. https://doi.org/10.1016/j.enbuild.2018.09.034

[3] Castaldo VL, Pisello AL. (2018). Uses of dynamic simulation to predict thermal-energy performance of buildings and districts: A review. WIREs Energy Environ 7: e269. https://doi.org/10.1002/wene.269

[4] Mutani G, Giaccardi F, Martino M, Pastorelli M. (2017). Modeling hourly profile of space heating energy consumption for residential buildings. Proceedings of INTELEC 2017, Gold Coast, Australia. https://doi.org/10.1109/INTLEC.2017.8214143

[5] Mutani G, Giaccardi F, Martino M, Pastorelli M. (2018). Modeling hourly variations in space heating energy consumption for office buildings. Proceedings of INTELEC 2018, Torino (IT): 7-11th October 2018. https://doi.org/10.1109/INTLEC.2018.8612372

[6] Lundström L, Akander J, Zambrano J. (2019). Development of a space heating model suitable for the automated model generation of existing multifamily buildings - a case study in Nordic climate. Energies 12: 485. https://doi.org/10.3390/en12030485

[7] Gao H, Koch C, Wu Y. (2019). Building information modelling based building energy modelling: A review. Applied Energy 238: 320-343. https://doi.org/10.1016/j.apenergy.2019.01.032

[8] Biserni C, Garai M. (2016). Energy balance and second law analysis applied to buildings: An opportunity for Bejan theory. International Journal of Heat and Technology 34(Special Issue 1): S185-S187. http://dx.doi.org/10.18280/ijht.34S125

[9] Streicher KN, Padey P, Parra D, Bürer MC, Schneider S, Patel MK. (2019). Analysis of space heating demand in the Swiss residential building stock: Element-based bottom-up model of archetype buildings. Energy \& Buildings 184: 300-322. https://doi.org/10.1016/j.enbuild.2018.12.011

[10] Verbekea S, Audenaert A. (2018). Thermal inertia in buildings: A review of impacts across climate and building use. Renewable and Sustainable Energy Reviews 82: 2300-2318. http://dx.doi.org/10.1016/j.rser.2017.08.083

[11] Li W, Putra SY, Yang PP. (2004). GIS analysis for the climatic evaluation of 3D urban geometry. GISDECO (2004). http://clamsitel.pbworks.com/w/file/fetch/45645330/OK $\% 20 \% 20 \% 20 \% 201$ i.pdf

[12] Sola A, Corchero C, Salom J, Sanmarti M. (2018). Simulation tools to build urban-scale energy models: A review. $\quad$ Energies 11: 3269. https://doi.org/10.3390/en11123269

[13] Ali U, Shamsi MH, Hoare C, O’Donnell J. (2018). GISbased residential building energy modeling at district scale. 4th Building Simulation and Optimization Conference, Cambridge, UK: 11-12 ${ }^{\text {th }}$ September 2018.

[14] Hamanah WMA, Kassas M, Mokheimer EMA, Ahmed CB, Said SAM. (2018). Comparison of energy consumption for residential thermal models with actual measurements. J. Energy Resour. Technol 141(3): 
032002 (18-1723). https://doi.org/10.1115/1.4041663

[15] Dodoo A, Tettey UY, Gustavsson L. (2017). Influence of simulation assumptions and input parameters on energy balance calculations of residential buildings. Energy 120: 718-730. http://dx.doi.org/10.1016/j.energy.2016.11.124

[16] Mutani G, Todeschi V. Energy balance at neighbourhood scale for residential buildings. Applied Energy (under revision), Elsevier.

[17] Mutani G, Todeschi V. (2017). Space heating models at urban scale for buildings in the city of Turin (Italy). Energy Procedia, PII: S1876-6102 (17) 33400. https://doi.org/10.1016/j.egypro.2017.07.445

[18] Carozza M, Mutani G, Coccolo S, Kaempf J. (2017). Introducing a hybrid energy-use model at the urban scale: The case study of Turin (Italy), Building Simulation Applications Conference, 2-s2.0-85050366851.

[19] Duffie JA, Beckman WA. (2013). Solar engineering of thermal processes. Fourth Edition, John Wiley \& Sons, ISBN 9780470873663. https://doi.org/10.1002/9781118671603

[20] Lucia U, Grisolia G. (2019). Exergy inefficiency: An indicator for sustainable development analysis. Energy Reports 5:

62-69. https://doi.org/10.1016/j.egyr.2018.12.001

[21] Lucia U, Grisolia G. (2017). Unavailability percentage as energy planning and economic choice parameter. Renew. Sustainable Energy Rev. 75: 197-204 https://doi.org/10.1016/j.rser.2016.10.064

\section{NOMENCLATURE}

\begin{tabular}{|c|c|}
\hline A & area, $\mathrm{m}^{2}$ \\
\hline $\mathrm{a}$ & albedo, - \\
\hline BCR & building coverage ratio, $\mathrm{m}^{2} / \mathrm{m}^{2}$ \\
\hline $\mathrm{BD}$ & building density, $\mathrm{m}^{3} / \mathrm{m}^{2}$ \\
\hline $\mathrm{BO}$ & building orientation, - \\
\hline $\mathrm{c}$ & specific heat capacity, $\mathrm{J} / \mathrm{kg} / \mathrm{K}$ \\
\hline $\mathrm{C}$ & $\begin{array}{l}\text { effective heat capacity of a conditioned } \\
\text { space (thermal capacity), } \mathrm{J} / \mathrm{K}\end{array}$ \\
\hline DHN & district heating network, - \\
\hline $\mathrm{F}$ & reduction factor, - \\
\hline GHG & greenhouse gas, - \\
\hline GIS & geographic information system \\
\hline $\mathrm{h}$ & $\begin{array}{l}\text { surface coefficient of heat transfer, } \mathrm{Wm} \\
{ }^{2} \mathrm{~K}^{-1}\end{array}$ \\
\hline hor & horizontal \\
\hline $\mathrm{H}$ & height, $\mathrm{m}$ \\
\hline HDD & heating degree days, ${ }^{\circ} \mathrm{C}$ \\
\hline $\mathrm{H} / \mathrm{W}$ & urban canyon height to width ratio, - \\
\hline I & solar irradiance, $\mathrm{W} / \mathrm{m}^{2}$ \\
\hline ID & identity code, - \\
\hline $\mathrm{L}$ & length of the cooling fin, $\mathrm{m}$ \\
\hline MOS & main orientation of streets, - \\
\hline NDVI & normalized difference vegetation index, \\
\hline
\end{tabular}

$\mathrm{T}$

$\mathrm{U}$

$\mathrm{V}$

V

W

\section{Greek symbols}

$\alpha$

B

Y

$\varepsilon$

\section{$\eta$}

$\rho$

$\lambda$

$\chi$

$\Phi$

\section{Subscripts}

a

avg

b

c

cs

e

extra

g

gn

hor

ht

H

int I

n

NIR

$\mathrm{ob}$

op

$r$

$\mathrm{S}$

se

sh

sol

$\mathrm{T}$

ve $\mathrm{V}$

W perimeter, $\mathrm{m}$

energy, kWh

volumetric airflow rate, $\mathrm{m}^{3} / \mathrm{s}$

thermal resistance, $\mathrm{m}^{2} \mathrm{KW}^{-1}$

surface to volume ratio, $\mathrm{m}^{2} / \mathrm{m}^{3}$

sky view factor, -

time, $\mathrm{s}$

temperature, ${ }^{\circ} \mathrm{C}$ or $\mathrm{K}$

thermal transmittance, $\mathrm{Wm}^{-2} \mathrm{~K}^{-1}$

wind velocity, $\mathrm{m} / \mathrm{s}$

volume, $\mathrm{m}^{3}$

distance between buildings, $\mathrm{m}$ absorption coeff. of solar radiation, solar height, ${ }^{\circ}$

surface inclination, ${ }^{\circ}$

emissivity of a surface for long-wave thermal radiation, -

system efficiency for space heating, density, $\mathrm{kg} / \mathrm{m}^{3}$

conductivity, $\mathrm{W} /(\mathrm{m} \cdot \mathrm{K})$

building inefficiency indicator, -

heat flow rate, thermal power, $\mathrm{W}$

air

average

building

convection

census section

external

extra flux

ground

gains

horizontal

heat transfer

heating

Internal

net

near infrared radiation

obstacles

opaque

radiative

surface

external surface

shading

solar

transmission

ventilation

window 